\title{
The role of behavioural economics in competition litigation
}

\section{Dame Vivien Rose*}

\begin{abstract}
In recent years, there have been major changes in economic theory from the development of behavioural economics, notably from Nobel prize for Economics winner Professor Richard Thaler. This article considers the role that behavioural economics could play in building a litigant's case in competition litigation in the High Court and of the Competition Appeal Tribunal.
\end{abstract}

Keywords: economics, behavioural economics, litigation, economic theory

\section{Introduction}

The role of economics and economists in competition law has, perhaps, been the feature that has marked this area of law out from many other specialisms. There have been major changes in economics theory in recent years with the development of behavioural economics. Last year, Professor Richard Thaler, co-author of the book 'Nudge' won the Nobel prize for economics. The prize was awarded, the Nobel Committee said, for incorporating psychologically realistic assumptions into analyses of economic decision-making. To quote the Nobel prize committee's citation:

By exploring the consequences of limited rationality, social preferences, and lack of self-control, Prof Thaler has shown how these human traits systematically affect individual decisions as well as market outcomes. ${ }^{2}$

The question this article explores is what role can or should behavioural economics play in the way the court or tribunal is invited to take the decisions which are needed as the building blocks of a case?

\section{Economic evidence in competition litigation}

There are two groups of questions in respect of which courts and tribunals allow expert economic evidence to be given at trial.
The first kind of question is helping the court to determine as a matter of fact what actually happened in the past. In a cartel damages case there are usually several major 'what actually happened' issues raised. The main ones are 'was there any cartel overcharge as the claimants will be asserting' or 'are the defendant cartelists right when they say that the cartel actually had little effect on the prices paid by the claimant customers'?

The second kind of question to which expert economic evidence is addressed is not establishing what actually happened in the past, but what would have happened in a counterfactual world. What would the price have been in the absence of the cartel, or in the absence of the dominant undertaking's exclusionary behaviour? It is in particular in this second kind of question that behavioural economics might be important. Can the approach championed by Professor Thaler and his colleagues help the court better predict what would have happened in the counterfactual world?

In his lecture given in December 2017 to the Nobel Academy, Professor Thaler describes the genesis of his thinking in the fate of a bowl of cashew nuts he put on the coffee table at the start of a dinner party he was hosting for fellow economics professors. ${ }^{3}$ After about half the cashews had been eaten, the guests expressed concern that they were spoiling their appetite for the supper they knew he was shortly about to serve them. Professor Thaler took the bowl of nuts into the kitchen out of their
Adapted from the keynote address given at the Mlex Competition Litigation Conference, Friday 14 September 2018, London. The views expressed are solely those of the author, and were made in a personal capacity.

1 R. Thaler, Nudge: Improving Decisions about Health, Wealth, and Happiness (Yale University Press, Connecticut, 2008).
2 Press release Nobel Committee: https://www.nobelprize.org/prizes/eco nomic-sciences/2017/press-release/.

3 R. Thaler, 'From cashews to nudges: the evolution of behavioural economics', https://www.nobelprize.org/prizes/economic-sciences/2017/thaler/lecture/ accessed 30 October 2018. 
reach. When he came back into the living room, the guests all thanked him. But why, he asked, were they happier when a choice had been taken away from them? They always had the option not to eat the cashews if they didn't want to spoil their appetite - they possessed perfect information enabling them to balance the present pleasure of eating them with the future embarrassment about not being able to finish their meal.

His guests' relief at being denied the choice of eating or not eating the nuts undermined, Professor Thaler realized, many decades of economic theory which assumes that more choices are always better. It assumes that if people are given the necessary information, they will make rational decisions to maximize their own welfare.

Except of course, people do not. Professor Thaler identified what he calls SIFs - 'supposedly irrelevant factors'. SIFs are features of the environment which influence the behaviour of human beings but do not influence the behaviour of the theoretical person (referred to as the 'Econ') on whom much of economic theory is based. A typical SIF that operates in a powerful way on people's decision-making is inertia, i.e. the tendency of people to fail to take action, even if it is explained to them how much they would benefit from taking that action. Another powerful SIF is loss aversion. People will typically avoid the risk of losing something they have even if that means foregoing the opportunity to gain something additional.

The cases below examine whether evidence of the behaviour of those in the market appears to clash with what conventional economics would predict. Do we see SIFs at work in how courts assess competition law issues? This article posits that we do, but we do not necessarily associate them with the expert evidence given in the case.

\section{Enron Coal Services Ltd. v. English Welsh \& Scottish Railway Ltd.}

In the litigation context, SIFs tend to emerge from the factual witness evidence recalling contemporaneous events, where such evidence is available to the court. A good example is the decision of the CAT in Enron Coal Services Ltd. v. English Welsh \& Scottish Railway $L t d .{ }^{4}$ In that case, the dominant railway company defendant had raised its prices to Enron for coal haulage services. One issue before the CAT was whether, in the 'but for world' where there had been no discriminatory pricing, Enron would have successfully bid for a coal haulage supply contract from a major customer Edison. Had Enron lost the profit on that Edison contract as a result of the Railway's abusive behaviour?

The crux of the case turned on whether Edison would have accepted the Enron bid in the 'but for world'. Enron argued that Edison would have reached its decision as to whether to enter into an agreement with Enron on a rational commercial basis. The governing factor in Edison's decision would have been the prices on offer by the different bidders. The claimant put forward economic evidence to show that Enron's price would have been the best. But against this economic evidence, the Tribunal heard evidence from Edison's buying director who put forward a number of reasons why Enron would not have got the contract. Some of these reasons are recognizable to an economist; for example, Edison already had a substantial supply contract with Enron in respect of another power station and did not want to be too dependent on one supplier. But one factor that was considered important by the CAT was that the Edison director in charge of procurement had dealt with Enron some years before in a contract which had gone very wrong. That contract had left, the witness said in his evidence, a bitter taste in the mouth. The CAT said in its judgment:

A point relied on by Enron was that the historical relations between Enron and Edison were not relevant to the outcome of the Edison Tender in the real world or the 'but for' world. Enron submitted that a rational economic operator would look for best value and not allow an incident in its previous commercial dealings to cloud its judgment. We regard that approach as erroneous and unrealistic. ... The nature and evolution of relations between parties can be an important consideration in deciding whether to enter into, maintain or alter a commercial relationship. ${ }^{5}$

So there was an example of what Professor Thaler would call a SIF - an irrelevant factor in any rational consideration by Edison of competing bids - that was nevertheless fatal to Enron's claim for damages.

However, this is not really an example of behavioural economics. Rather, it is an example of a one-off idiosyncratic bad experience suffered by the one witness who unfortunately for Enron - just happened then to be the person in charge of awarding the next contract. Economics can never really involve the study of those kinds of factors.

The clue to the distinction to be made lies in the title of a book written by another well-known behavioural economist Dan Ariely. His book is called Predictably 
Irrational: the hidden forces that shape our decisions. ${ }^{6}$ Professor Ariely is a Professor of Psychology and Behavioural Economics at Duke University and is the founder and principal of the Center for Advanced Hindsight. The importance of the behavioural economists' work is not just in concluding that often people act irrationally. The key insight is that they do so in predictable ways. This means that their apparently irrational conduct is as amenable to study and modelling as the behaviour of the non-existent rational Econ. That is why this new branch of economics can be used to predict outcomes either for the future or when considering a counterfactual for the past.

\section{Flynn Pharma and Pfizer v. CMA}

Another case that illustrates this point is the judgment of the CAT in Flynn Pharma and Pfizer v. CMA. ${ }^{7}$ In that case, the CAT set aside the CMA's finding that Flynn Pharma and Pfizer abused their dominant position by charging excessive prices for an anti-epilepsy drug called phenytoin sodium. One factor that was relevant to the analysis of market definition and market power was the fact that the drug had a narrow therapeutic index. That means that it is very important that patients stabilized on a particular brand of the drug stay on that brand because very small differences between that product and a different brand of the same product might make a significant difference to the efficacy of the drug. The CMA found in the infringement decision that the importance of continuity of supply was a significant barrier to entry. Given that doctors were being told to keep prescribing the same brand of product to their patients, any new brand trying to enter the market would struggle to become established.

The CAT explained the detailed guidance on prescribing that the Department of Health issued over the years to doctors emphasizing the need to maintain continuity. Yet the CAT records that notwithstanding the clinical guidance, it was common ground between the parties that in fact the vast majority of prescriptions for phenytoin sodium capsules which had been available for analysis were generic or open, i.e. not specifying any brand or manufacturer. ${ }^{8}$ Thus, the CAT concluded, the doctors appeared largely to be either ignoring the Department of Health Guidance directed at them or leaving it to pharmacists to implement rather than applying it themselves. The CAT stressed that what mattered for its analysis of market definition and market power was how the clinical guidance was actually interpreted and applied by pharmacists. What the CAT ultimately found was that there was a barrier to entry here but that the position was not as unequivocal as the CMA's decision had concluded.

That approach of the CAT was possible in circumstances where there was quantitative evidence about prescribing habits which could be analysed and presented. This enabled the CAT to see that, perhaps surprisingly, the effect of clear guidance about prescribing this product was more limited than one would think.

However, suppose the same issue about barriers to entry arising from the NHS guidance had arisen in the context of trying to work out what would have happened in a counterfactual world. Would a party have succeeded with a submission arguing that clear guidance appearing to strongly favour the incumbent product was irrelevant, and the court or tribunal should conclude that doctors and pharmacists will largely ignore it?

Interestingly any economist supporting that submission would be able to point, as the CAT did, to the countervailing effect of commercial incentives set up by the reimbursement mechanisms under the NHS rules. Those commercial incentives were themselves introduced by the NHS to try to combat the inertia of doctors and pharmacists to change their prescribing habits once cheaper generic drugs come onto the market when the patent on the branded drug expires. It is difficult to know how far such an argument would have got.

\section{The power of zero - evaluating free services}

The other example of an important SIF is what Professor Dan Ariely describes as the power of zero. In his book Predictably Irrational is a chapter called 'The Cost of Zero Cost'. ${ }^{9}$ The chapter opens with some questions have you ever gathered up free pencils, key chains and notepads at a conference even though you have to carry them home and would only throw most of them away? He goes on to examine what is it about zero costs that people find so irresistible. Why does 'free' make people so happy?

\subsection{The cost of zero cost}

Professor Ariely describes an experiment where he offered two kinds of chocolate to students who were buying their lunch at the cafeteria. They could have a (Harper Collins, New York, 2008).

7 Flynn Pharma and Pfizer v. CMA [2018] CAT 11.
8 Ibid, para 129

9 Ariely (fn 6). 
good quality Lindt truffle for 15 cents and a more humble Hershey Kiss at 1 cent. About 73\% of students chose the truffle and 27\% chose the Hershey Kiss. He then discounted both prices by 1 cent so that the price was the same relative to each other - the truffle was 14 cents and the Hershey Kiss was free. The Hershey Kiss became the favourite with $69 \%$ of customers (instead of $27 \%$ ) now choosing the Kiss and only $31 \%$ (instead of $73 \%$ ) choosing the truffle.

According to standard economic theory, the price reduction should not have led to any change in behaviour. Why then do people display an irrational urge to jump for a free item even when it is not really what they want? $\mathrm{He}$ describes the reason as loss aversion - humans are intrinsically afraid of loss and the allure of free is tied to this fear. There is no visible possibility of loss when we choose an item that is free - we think it is impossible for getting something for free to be a bad decision. Of course rationally people know that that is wrong - free can trap people into making the wrong choice between two options.

\subsection{Streetmap.EU v. Google}

The provision of free services has been perplexing competition authorities for a while now. As Mr. Justice Roth said at the start of his judgment in Streetmap.EU v. Google, ${ }^{10}$ the development of commerce over the internet presents a challenge for competition law. It is obviously important that competition law should apply fully and effectively to what has become a very significant form of commerce. However, the appropriate application of some of the concepts of competition law must have regard to the particular characteristics of this new environment.

The essence of StreetMap's complaint was that Google was included in the OneBox which appears at the side of the screen, and when someone searches for a particular location a map from Google Maps appears and not a map from one of Google Maps' competitors. The court rejected an analysis of the alleged abuse as a bundling abuse. ${ }^{11}$ The user who sees the new-style Maps OneBox is under no obligation to click on it or to use Google
Maps. He or she remains free, without penalty, to use any other online mapping provider or none at all.

It is interesting to note that, early on in the judgment, the court made an orthodox statement to the effect that since general search engines are free to users, they compete on quality. ${ }^{12}$ This covers such matters as the relevance of the results, speed, convenience, and the attractiveness of the search entry results page. However, the analysis went on to acknowledge the SIFs are at work here. In concluding that the correct characterization of the alleged abuse was the use of the undertaking's power on the dominated market to leverage its position in the associated market, Mr. Justice Roth gave as an example something raised with the economic experts at trial. If a supermarket was dominant in a discrete market for supermarket grocery retailing, but also produced its own-label brands of tea, sugar and biscuits which competed with those of third party manufacturers, it could be an abuse if the supermarket reserved the preferential display positions for its own brands, notwithstanding that customers who wanted other brands could still find them elsewhere in the store. ${ }^{13}$

In his Nobel lecture, Professor Thaler referred to supermarket shelving decisions as strong SIFs. It should not make any difference to the consumer where the product is displayed since that has no influence on any factor that the customer would rationally take into account when choosing, i.e. it does not affect price or quality. But supermarkets and their suppliers spend a great deal of time and money working out how best to display their products to their mutual benefit.

\section{Conclusion}

At the close of Professor Thaler's lecture at the end of last year, he said that understanding human nature can improve the explanatory power of economics and help us devise solutions to public policy problems. ${ }^{14}$ To conclude, lawyers and judges like to think that understanding human nature is key to making and enforcing good law. It seems that the recent developments described have a bright future in competition law litigation. 